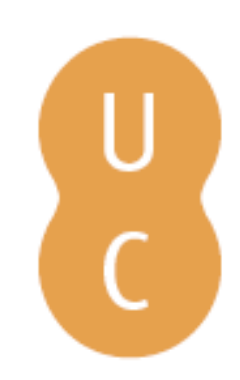

\title{
pombalina
}

\section{Horácio em França: complexo escolar e sabedoria poética}

Autor(es): Cordeiro, Cristina Robalo

Publicado por: Centro de Estudos Clássicos e Humanísticos; Imprensa da Universidade Publicado por: de Coimbra

URL

persistente: URI:http://hdl.handle.net/10316.2/32068

DOI: $\quad$ DOI:http://dx.doi.org/10.14195/978-989-8281-11-1_12

Accessed : $\quad$ 26-Apr-2023 12:27:33

A navegação consulta e descarregamento dos títulos inseridos nas Bibliotecas Digitais UC Digitalis, UC Pombalina e UC Impactum, pressupõem a aceitação plena e sem reservas dos Termos e Condições de Uso destas Bibliotecas Digitais, disponíveis em https://digitalis.uc.pt/pt-pt/termos.

Conforme exposto nos referidos Termos e Condições de Uso, o descarregamento de títulos de acesso restrito requer uma licença válida de autorização devendo o utilizador aceder ao(s) documento(s) a partir de um endereço de IP da instituição detentora da supramencionada licença.

Ao utilizador é apenas permitido o descarregamento para uso pessoal, pelo que o emprego do(s) título(s) descarregado(s) para outro fim, designadamente comercial, carece de autorização do respetivo autor ou editor da obra.

Na medida em que todas as obras da UC Digitalis se encontram protegidas pelo Código do Direito de Autor e Direitos Conexos e demais legislação aplicável, toda a cópia, parcial ou total, deste documento, nos casos em que é legalmente admitida, deverá conter ou fazer-se acompanhar por este aviso.

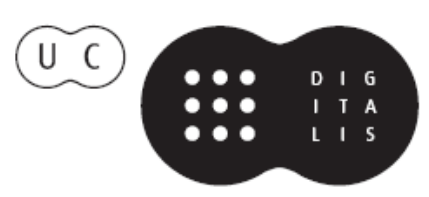




\section{Horácio \\ e a sua \\ Perenidade}

\section{Maria Helena Rocha Pereira, José Ribeiro Ferreira e Francisco de Oliveira}

IMPRENSA DA UNIVERSIDADE DE COIMBRA 


\title{
Horácio em França. Complexo escolar e Sabedoria Poética
}

\author{
Cristina Robalo Cordeiro \\ Universidade de Coimbra
}

O estudo da recepção de Horácio em França parece, à primeira vista, um jogo de criança. A matéria é excessiva: antes mesmo de qualquer inquérito sério, muitos são os nomes que surgem em catadupa ao espírito, da Idade Média ao século XX, de Jean de Meung a Fernand Mazade, passando por Eustache Deschamps, Montaigne, Vauquerin, Guez de Balzac, Boileau, La Fontaine, Diderot, Beaumarchais, Chénier, Leconte de Lisle, Heredia, etc., todos os escritores, grandes e menos grandes, respondem à chamada. Com efeito, tão considerável é a sua influência na literatura francesa que os historiadores negligenciam a sua relação metódica: tomemos como exemplo o index nominum da Histoire de la Littérature française de Gustave Lanson, onde não encontramos mais do que uma vintena de referências ao poeta latino, embora este historiador da literatura nos mostre nas páginas consagradas ao "Grand Siècle" que o pensamento estético e moral de Horácio é consubstancial ao espírito do classicismo francês. Esta omnipresença foi, no entanto, objecto de uma análise sistemática numa obra, já antiga, de J. Marmier: Horace en France au XVII siècle, onde sobressai a ideia de que o autor das Odes, das Sátiras e das Epistolas foi não apenas imitado, mas verdadeiramente "clonado", como hoje diríamos. Quase não é, pois, excessivo afirmar que Horácio está para a literatura francesa dos séculos XVII e XVIII como a "King James's version" da Bíblia para as letras inglesas da mesma época. Para quem dispõe de apenas alguns minutos, a esmagadora preponderância da matriz horaciana impõe a escolha de uma estratégia de exposição.

Seria seguramente absurdo e sobretudo sobrehumano pretender inventariar perante vós as obras que, directamente ou não, possuem a marca do escritor de quem celebramos hoje a memória: seria um catálogo tão fastidioso quanto necessariamente incompleto. Um trabalho, de natureza mais filológica, mas quase não menos vertiginoso, poderia procurar repertoriar os estudos de erudição consagrados em França a Horácio, desde os tempos mais recuados: lembraríamos assim a importância decisiva da contribuição dos humanistas franceses para a fixação dos textos a partir dos manuscritos conservados nos grandes mosteiros da Gália franca. A lista destes escrupulosos editores e comentadores iria de um Henri Estienne a uma Denys Lambin, para prosseguir, século após século, até aos nossos dias, onde, depois de tão preciosos trabalhos de eminentes latinistas como Eugène Benoist, ou Abée Lejay - para citar apenas dois -, um Pierre Grimal soube, por assim dizer, rejuvenescer o rosto universitário do nosso velho poeta. Também o corpus constituído pelo conjunto das traduções e das adaptações é quase infinito: de Amadis Jamyn, amigo de Ronsard, a Mario Meunier, é toda uma biblioteca que teríamos que 
percorrer a passos largos: não esqueçamos, a este propósito, que em França, como aliás em toda a Europa culta, traduzir Horácio constituiu uma espécie de passatempo para uma burguesia alimentada desde a infância pelas Belleslettres: é o que ilustra em modo algo caricatural uma comédia de Courteline, Client sérieux, onde um funcionário que perde o emprego se despede do seu patrão dizendo: "Adieu! Je vais traduire Horace". Uma tal réplica faz-nos hoje sorrir (ou sonhar)!

Renunciando a longas enumerações, poderia ter privilegiado um exemplo característico de "inutrição" horaciana tentando mostrar, com um caso particular, a assimilação por parte de um poeta francês dos processos e dos temas do modelo latino: a única análise da ode consagrada por Ronsard "À la fontaine de Bandusie" forneceria assim uma magnífica amostra de literatura comparada na medida em que o grande lírico francês, longe de se contentar em reproduzir em octossílabos a célebre Ode XIII do Livro III celebrando a "fons Baldusiae", revive-a do interior aclimatando-a à sua terra natal, a Touraine.

Antes de tomar um partido definitivo, hesitei um pouco em agrupar as minhas considerações num quadro panorâmico que teria recapitulado a história da literatura francesa seguindo, como na bolsa de valores financeiros, as altos e baixos da cotação horaciana: esta apresentação ter-me-ia permitido recorrer à tecnologia do "power point". Mas não estou certa de que o encanto das humanidades sobreviva à electrónica... Imaginai, no entanto, que vedes num ecrã de computador, à esquerda e a meio, um quadrado verde representando a Renascença: uma elite de espíritos, de Du Bellay a Montaigne, abraça com entusiasmo a língua e a cultura greco-latinas: Horácio recebe o seu tributo de homenagem, mas não se destaca do pelotão pois que, no seu gigantesco apetite humanista, a época absorve tudo e todos, e nada rejeita. Segui agora o ponto luminoso da minha lâmpada virtual até a um triângulo amarelo onde figura a palavra "Classicismo": é o momento do apogeu, Horácio está no zénite do seu poder. Não é já necessário pronunciar o seu nome pois que a sua concepção da arte e da vida se confundem inteiramente com a ideologia do "honnête homme": Horácio é naturalizado francês, cortesão solícito não já de Augusto mas do Rei Sol. O triângulo abraça dois séculos - de 1620, onde "Enfin Malherbe vint", até 1820, ano que assiste ao triunfo do lirismo lamartiniano. $\mathrm{E}$, com efeito, o meu power-point cai brutalmente e vem gravitar em torno de uma oval vermelha: o Romantismo. É a revolta dos "Jeune-France" contra a velha escola clássica, contra a sua estética da medida, contra a sua ética do "juste milieu”, contra as regras e os géneros, insurreição que se volta, ao mesmo tempo, contra a herança horaciana de que Boileau, o severo legislador da República das Letras, é o herdeiro universal. A liberdade shakespiriana reina então nos palcos parisienses, deitando às ortigas, entras outras restrições, a divisão da tragédia em cinco actos, prescrição directamente saída da "Epístola aos Pisões”. Mas este momento de eclipse não durará mais do que o tempo de uma geração, e aliás este eclipse não é total se pensarmos que um Alfred de Muset, romântico irónico, se apoia na Ode 9 do livro III para pôr Horácio a dialogar com Lídia. E é tempo agora de visualizar no meu ecrã imaginário 
uma seta descendente a apontar para um círculo azul: eis chegada a hora do Parnasso, da Arte pela Arte, do culto da forma e da perfeição plástica, noções resumidas por Théophile Gautier na sua "Art poétique", alusão explícita a Horácio:

\author{
Tout passe, \\ L'art robuste seul a l'éternité \\ Les dieux eux-mêmes meurent \\ Mais les vers souverains \\ Demeurent \\ Plus forts que les airains.
}

Uma tal exaltação do trabalho, só ele capaz de assegurar a perenidade da obra de arte, é a reafirmação, em pleno século XIX, do pancalismo horaciano contra o laisser-aller libertário do romantismo. E finalmente, à direita do quadro, podeis ver uma constelação informe de nomes de escritores ou de "escreventes": Horácio apenas existe sob a forma de membra disjecta, de "citações" ornamentais, embelezando artigos, prefácios e dissertações. Horácio, com excepção de algumas notáveis excepções, deixou de ser lido no texto, e não é conhecido senão por intermédio das "páginas rosa" do dicionário Larousse, onde, no entanto, entre outros autores latinos, permanece largamente o mais representado (contei 27 menções, Virgílio tem menos de metade). Passou o tempo em que os estudantes deviam ser capazes de "semear", nas suas composições literárias, uma passagem das Epistolas, das Sátiras ou das Odes, caídas no domínio público: "Nil admirari", "Ab ovo", "In medias res", "Aurea mediocritas" e outros "Odi profanum vulgus"... Este regime da citação breve releva mais de uma semiologia "à la Barthes" do que de um estudo sério da recepção de Horácio no século XX, pois que ele e os seus companheiros das letras greco-latinas não são doravante senão signos furtivos, vestígios prestigiados mas cada vez mais impalpáveis de uma Autoridade cultural abolida.

Tudo o que precede, lista, quadro, inquérito, é o que eu poderia ter feito mas não farei hoje aqui, por falta de tempo e, sobretudo, de conhecimentos. Optei por uma solução de natureza mais retórica, isto é, mais económica. Proponho então que retomemos a questão desde início. Apoiando-me em alguns exemplos privilegiados, traçarei assim um esquema simples que me permitirá balizar a evolução de uma situação. Parece-me possível, como num jogo, resumir o percurso da recepção francesa de Horácio - deixando de lado o campo dos trabalhos eruditos - segundo uma lei dos três estados: o estado canónico, o estado crítico e (com a vossa permissão, pois que é preciso acertar o passo com o nosso tempo) o estado rizomático. Escolherei para ilustrar o estado canónico um exemplo sem dúvida inesperado e, em certa medida, anacrónico, o de Rimbaud, fiel até ao limite das suas audácias extremas, à sua formação primeira. $\mathrm{O}$ estado crítico, atravessado pelo paradigma escolar, está patente no grande poema "À propos d'Horace" das Contemplations, mesmo se o rancor de Victor Hugo pelos seus professores de latim não o impede de 
apreciar a poesia horaciana. Mas é, todavia, o romantismo que, pela sua voz, põe em causa o dogma literário à difusão do qual Horácio se encontra ligado. O estado rizomático permitir-nos-á considerar uma época - a da emergência da modernidade literária - onde o texto horaciano se disseminou na escrita: Horácio já não é agora um modelo único - a imitar ou a destruir - mas uma referência de sentido múltiplo que cada escritor utiliza como entende.

I. Consideremos em primeiro lugar o cânone horaciano, tal como o conheceram na escola gerações de futuros escritores. Impõe-se desde o aparecimento dos primeiros colégios jesuítas e conhece uma verdadeira hegemonia nos séculos 18 e 19. Na formação do espírito literário clássico, possui um estatuto privilegiado, nem mesmo disputado por Aristóteles na medida em que, como nos diz Marmier, só os "doutos" têm acesso à Poética enquanto todos os "honnêtes gens", que foram os principais difusores do classicismo, leram e estudaram Horácio (e Quintiliano) nas aulas. Acresce que é ainda rapidamente "afrancesado" por Boileau, cujas Satires, Epîtres e sobretudo a Art Poétique o tornam familiar a todo um público feminino e mundano. Não se trata aqui de mostrar a forma como Boileau, antigo aluno do colégio de Harcourt, pôde, adaptando-o, conferir ao pensamento de Horácio (e aos seus amáveis conselhos aos Pisões) uma rigidez doutrinária, de catecismo. Aliás, a crítica admitiu desde há muito que Boileau, longe de fundar a doutrina clássica, não fez senão consagrá-la e que os escritores não esperaram o seu Art poétique (tardio, de 1674) para se impregnarem do espírito horaciano. E podemos ainda afirmar que Boileau "escolarizou" Horácio, tornando-se Art poétique muito rapidamente um clássico do ensino secundário.

Note-se que esta origem largamente escolar da cultura horaciana em França não prejudicou, de forma alguma, a popularidade do nome de Horácio. Como se Boileau, chamando a si o fardo didáctico da epístola aos Pisões, libertasse Horácio das suas funções pedagógicas para que ele pudesse ser apreciado pelo jovem público apenas pelo seu bom humor. Poderia, para ilustrar o meu propósito, tomar como exemplo La Fontaine ou Voltaire, outro epicurista cuja Epístola a Horácio é a homenagem rendida a um mestre único na arte de viver. E foi nos bancos do colégio Louis-le-Grand que Voltaire aprendeu a respeitar e a amar o "voluptueux Horace":

Qui, facile en tes vers et gai dans tes discours,

Chantas les doux loisirs, les vins et les amours.

Para marcar bem a extensão e a permanência da influência horaciana na escola, vou deixar de lado a época clássica para me debruçar sobre um autor cujo nome não costuma geralmente ser associado às letras latinas. Refiro-me a Rimbaud. Se quisermos medir toda a novidade de Une Saison en enfer, é no entanto menos a Baudelaire e a Hugo e mais a Horácio que nos devemos reportar. Tomemos a prosa alucinante de Illuminations: eis pela primeira vez na literatura uma escrita que parece romper com o princípio sacrossanto da 
clareza conceptual definida primeiro por Horácio nos vv. 309-311 da Epistola aos Pisões, e depois por Boileau, num dístico famoso:

Ce qui se conçoit bien sénonce clairement, Et les mots pour le dire arrivent aisément.

(Art poétique, I, v. 153-154)

Mas este intelectualismo clássico, onde se encontram Boileau e Descartes, não é repudiado por Rimbaud, que o estende a domínios sensoriais que até então lhe estavam vedados. Rimbaud leva ao extremo o poder representativo da linguagem, intensifica a clareza, a precisão até ao deslumbramento, até à iluminação. É a razão pela qual, sem dúvida paradoxalmente, podemos ainda arrumá-lo entre os "horacianos". Com Rimbaud, escolhi, reconheço-o, um caso extremo de obediência ao código escolar (e precisaria de mais tempo e de mais espaço para vos convencer). Um argumento psicológico vem no entanto em meu auxílio: excelente aluno, Rimbaud nunca sentiu como um peso, uma "seca" a disciplina imposta pelas recomendações da Arte poética, tanto de Boileau quanto de Horácio, tendo-as, pelo contrário, perfeitamente interiorizado. E se há nele um complexo escolar, não é por certo o do "cancre" mas bem pelo contrário o do "fort en thème" que assimila intimamente os seus modelos até à identificação total. E chego à prova textual: uma composição escolar redigida a 6 de Novembro de 1868, quando tinha apenas 14 anos, onde deveria desenvolver, em três horas e meia, o tema tratado por Horácio na célebre passagem autobiográfica das Odes VI, livro II: "Me fabulosae Vulture in Apulo" ("dans mon enfance, un jour que j'étais las de jouer et de sommeiller sur les bords du Vultur d'Apulie, de merveilleuses colombes me couvrirent d'un feuillage nouveau...”). Não perderei tempo a comentar as condições impostas: 3 h e meia, 60 hexâmetros: só um catedrático das letras clássicas seria hoje capaz de um tal feito! Também não vos lerei os versos latinos de Rimbaud nem a tradução que deles foi feita. Assinalarei apenas o à-vontade com que o jovem Rimbaud se identifica com o jovem Horácio, também ele criança fogosa e coroada com o louro de Apolo: “TU VATES ERIS”, serás poeta. Desta profecia de Febus, faz o aluno de Charleville seguramente a marca da sua própria vocação. A assimilação é total. Ele é Horácio criança, bem querido das Musas.

2. Rimbaud, a imagem mesmo da revolta, da adolescência insubmissa, não se insurgiu contra o mestre latino nem contra os seus professores de retórica e nomeadamente o seu amigo e confidente Georges Izambart. Pelo contrário! Magnífico produto da escola imperial, parece não ter sofrido com os vexames e troças que levaram Victor Hugo a combater violentamente os seus antigos professores no longo poema XIII do livro I das Contemplations:

Marchands de grec, marchands de latin! Cuistres, dogues!

Philistins, magisters! Je vous hais, pédagogues ! 
E assim por diante. O poema "À propos d'Horace" data de maio de 1831, isto é, sucede (em escassos meses) à Batalha de Hernani, vitória estrondosa de uma juventude cabeluda e liberal. $O$ texto exigiria uma leitura integral, o que não poderei aqui fazer. Citarei apenas algumas passagens que exemplificam bem o meu segundo ponto: mesmo se o poeta tem o cuidado de distinguir Horácio dos horríveis "pions" que o utilizam para atormentar tenros internos, a verdade é que a epístola aos Pisões serve realmente de instrumento de tortura:

Grand diable de seize ans, j'étais en rhétorique !

Que d'ennuis! De fureurs !, de bêtises! - gredins !-

Que de froids châtiments et que de chocs soudains!

« Dimanche en retenue et cinq cents vers d'Horace!

Depois de uma nova chuva de invectivas contra os seus carrascos e da evocação do idílio falhado (Victor Hugo tinha nesse domingo "rendez-vous avec la fille du portier"), o poeta faz justiça ao amigo de Virgílio em versos deliciosos onde o inferno escolar cede o lugar ao universo encantado da poesia horaciana:

Horace! Ô bon garçon!

Qui vivais dans le calme et selon la raison,

Et qui t'allais poser, dans ta sagesse franche,

Sur tout, comme loiseau sur la branche,

Sans peses, sans rester, ne demandant aux dieux

Que le temps de chanter ton chant libre et joyeux.

O poema - que deveríamos ler integralmente - dá testemunho da íntima familiaridade de Hugo com o mundo latino, onde se sente como em sua casa. A sua querela não o opõe, pois, a Horácio, em quem reconhece, para lá dos séculos, um companheiro fraterno, mas antes aos "horribles bonshommes" que esmagam o espírito, brutalizam a alma e o corpo da criança em nome de uma pedagogia opressora. O melhor comentário do poema de Victor Hugo, pelo menos da sua significação profunda, encontra-se no capítulo que Gaston Bachelard consagra, no seu livro Lautréamont, ao que chama "les complexes de la culture". Aí debruça-se sobre "la psychologie de la brimade" mostrando que para Isidore Ducasse, como para muitos outros, entre os quais Victor Hugo, "la période culturelle de l'adolescence a été une période douloureuse, intellectuellement névrosante" (Lautréamont, p.62). E é sobretudo o professor de retórica que exerce com sadismo a sua autoridade intelectual, o que é "un drame de la culture, un drame né dans une classe de rhétorique, un drame qui doit se résoudre dans une oeuvre littéraire" (id., p.74). Apetece-nos acrescentar: é o que acontece com Lautréamont e com Victor Hugo, insubmissos que reagem pela criação artística à opressão escolar. O escândalo é que os mais belos nomes da literatura, e nomeadamente o de Horácio, foram tornados cúmplices da vontade de poder muitas vezes mesquinha. Por isso Victor Hugo termina o seu poema fazendo apelo a uma pedagogia libertadora onde "[on] 
n'instruira plus les oiseaux par la cage" e onde "tout en laissant au sommet des études / les grands livres latins et grecs, ces solitudes", é "en les faisant aimer qu'on les fera comprendre".

3. Ora, é um facto que nos reconciliamos, com a ajuda da maturidade, com autores que a coacção escolar nos havia incitado a rejeitar depois de um rápido julgamento, com 16 ou 18 anos, e que enfim compreendemos que, na expressão de Gide, o classicismo é um "romantisme dompté" e não uma fria e enfadonha escola de boas maneiras literárias. Para ilustrar, de forma sucinta, o meu terceiro ponto, o estado rizomático, a escolha é grande pois basta mostrar que Horácio está "un peu, partout" sem estar verdadeiramente muito "nulle part”. Teria podido recorrer a Alain e aos seus Propos, à Romain Rolland e ao seu "Carmen Saeculare", pelo qual, em alusão explícita à ode horaciana, saúda o século 20 nele apontando as grandes forças espirituais. Ou ainda, num campo diferente, a Anatole France e a Paul Bourget. Ou até mesmo a Apollinaire. De facto, a imagem do rizoma tema a vantagem de nos mostrar um pensamento ressurgindo onde não era esperado: assim aparece Horácio, antes de 1914, em autores muito distantes pela ideologia e pela concepção da arte, sem que essas aparições estejam envoltas em polémica. A presença de Horácio nos volumes de $\hat{A}$ la recherche du temps perdu traz-se assim as mais saborosas surpresas: estou a pensar, por exemplo, em certa passagem de Sodome et Gomorrhe, em que Brichot, o professor da Sorbonne, pilar do salão dos Verdurin, cita Charlus um verso das Odes (I,1): "Maecenas atavis edite regibus". "Qu'estce que vous dites? Demanda Mme de Verdurin à Brichot [...]. - Je parlais, Dieu m'en pardonne d'un dandy qui était la fleur du gratin (Mme Verdurin fronça les sourcils), environ le siècle d'Auguste (Mme Verdurin rassurée par l'éloignement de ce gratin prit une expression plus sereine), d'un ami de Virgile et d'Horace qui poussait la flagornerie jusqu'à lui envoyer en pleine figure ses ascendances plus qu'aristocratiques, royales, en un mot je parlais de Mécène, d'un rat de bibliothèque qui était ami d'Horace, de Virgile, d'Auguste. Je suis sûr que M. de Charlus sait très bien qui est Mécènes » (Recherche, III, p.343). É interessante ver a habilidade com que Proust, através da sua personagem Brichot, sabe espicaçar o ciúme de Mme Verdurin em relação a um "dandy" romano, da mais autêntica nobreza, e que tem o mau gosto de não frequentar o seu salão...

Já Claudel, sendo poeta, mantém com Horácio laços mais substanciais e, de algum modo, mais profissionais do que Proust. E desde logo pelos títulos dos seus grandes textos: Art poétique, Cinq grandes Odes. A primeira dessas Grandes Odes invoca as nove Musas: "Les Neuf Muses! Aucune n'est de trop pour moi!»

Sem que o nome de Horácio figure em nenhum destes versos, os comentadores, como Gérard Antoine, não hesitam em reconhecer claros ecos do poema latino. Recordação escolar ou reatar tardio com uma tradição que redescobria também o neo-clacissismo e a Belle Époque? Horácio, com Virgílio, é o seu autor preferido: Claudel repete-o várias vezes no seu Journal e 
estamos em crer que não é a arte de viver que mais o impressiona, na obra de Horácio, mas antes a arte tout court, a impecável execução do verso acolhendo o movimento rítmico em toda a sua amplitude conferindo-lhe um carácter de necessidade.

A homenagem que rende a Boileau, em 1911, conviria igualmente a Horácio: "Le vers n'est pas pour lui, comme pour les romantiques, un instrument de vanité personnelle et de parade, mais le moyen d'ôter à la parole la possibilité d'être autre [...]»(Oe. En prose, p.438). Os Cahiers de Valéry citam também com frequência Horácio, mas mais uma vez aqui sem rancor: o complexo escolar foi ultrapassado.

Em 1937, na celebração do segundo milénio de Horácio, Anatole Monzie escreveu: "Je suis de ceux qui au collège détestèrent Horace [...]: on nous avait fabriqué, nous nous étions fait une image fort prudhommesque de ce poète officiel [...]. J'ai réctifié mon jugement d'écolier ». Essa declaração sincera, insólita na pena de um ministro Educação nacional, poderia ter sido subscrita por muitos escritores da Terceira República. $\mathrm{O}$ meu pequeno inquérito termina com esta república que Thibaudet definira como a "republique des Proffesseurs". A presença de Horácio na literatura francesa sobreviveu à derrocada Maio de 1940, que é também a do eudemonismo imanente às humanidades clássicas? Tememos que não! A única esperança que nos resta, que lhe resta, cabe inteira nas duas palavras carpe diem inscritas nos muros de Maio de 68, fraterna saudação ao aluno rebelde do severo Orbilius. 